Emily L. Smart, MA*

Alan J. Gow, PhD*

Ian J. Deary, $\mathrm{PhD}$

Correspondence to

Dr. Gow:

A.J.Gow@hw.ac.uk

or Prof. Deary:

I.Deary@ed.ac.uk
Supplemental data at Neurology.org

\title{
Occupational complexity and lifetime cognitive abilities OPEN
}

\section{ABSTRACT}

Objective: To examine associations between complexity of main lifetime occupation and cognitive performance in later life.

Methods: Occupational complexity ratings for data, people, and things were collected from the Dictionary of Occupational Titles for 1,066 individuals ( $m e n=534$, women $=532$ ) in the Lothian Birth Cohort 1936. IQ data were available from mean age 11 years. Cognitive ability data across the domains of general ability, processing speed, and memory were available at mean age 70 years.

Results: General linear model analyses indicated that complexity of work with people and data were associated with better cognitive performance at age 70 , after including age $11 \mathrm{IQ}$, years of education, and social deprivation.

Conclusions: The current findings are supportive of the differential preservation hypotheses that more stimulating environments preserve cognitive ability in later life, although the continued effects into old age are still debated. Studies that have early-life cognitive ability measures are rare, and the current study offers interesting prospects for future research that may further the understanding of successful aging. Neurology ${ }^{\circledR}$ 2014;83:2285-2291

\section{GLOSSARY}

DOT = Dictionary of Occupational Titles; $\mathbf{g}=$ general cognitive ability; LBC1936 = Lothian Birth Cohort 1936; MHT = Moray House Test; PCA = principal component analysis; SMS1947 = Scottish Mental Survey 1947.

There is a growing body of research suggesting that more stimulating lifestyles, including more complex work environments, are associated with better cognitive outcomes in later life. ${ }^{1-5}$ Underlying mechanisms behind this association are not fully understood, although it is suggested that more stimulating environments increase "cognitive reserve,"6 which subsequently protects against the effects of aging - normal ${ }^{7}$ or pathologic ${ }^{8,9}$ - on the brain. This is described by the differential preservation hypothesis. ${ }^{1,2,7}$ By contrast, given the stability of cognitive performance across the life course, others have highlighted that an individual's level of engagement in complex activities might be a consequence of differences in prior cognitive ability. ${ }^{10,11}$ This latter possibility is often referred to as preserved differentiation. ${ }^{1,2}$

Limitations in the literature are the absence of measures of prior cognitive ability ${ }^{1-3}$ and the use of brief cognitive assessments. ${ }^{4,5}$ Using the Dictionary of Occupational Titles (DOT), participants in the Lothian Birth Cohort 1936 (LBC1936) were assigned scores summarizing the occupational complexity of their work with data, people, and things. Associations were examined between 4 cognitive domains (age 70 IQ, general cognitive ability, memory, and processing speed) and occupational complexity with data, people, and things. Cognitive ability scores from childhood were included in the analysis to establish whether associations between occupational complexity and adult cognitive ability were independent of prior ability.

\footnotetext{
*These authors contributed equally to this work.

From the Department of Psychology (E.L.S., I.J.D.), and Centre for Cognitive Ageing and Cognitive Epidemiology (A.J.G., I.J.D.), University of Edinburgh; and Department of Psychology (A.J.G.), School of Life Sciences, Heriot-Watt University, Edinburgh, UK.

Go to Neurology.org for full disclosures. Funding information and disclosures deemed relevant by the authors, if any, are provided at the end of the article. The Article Processing Charge was paid by the institution.

This is an open access article distributed under the Creative Commons Attribution License, which permits unrestricted use, distribution, and reproduction in any medium, provided the original work is properly cited.
} 
METHODS Participants. The LBC1936 is a longitudinal study of aging. All participants were born in 1936, and most took part in the Scottish Mental Survey 1947 (SMS1947), a national survey completed by almost all 11-year-olds at school in Scotland. The LBC1936 comprises 1,091 participants (548 men and 543 women) who were recruited at a mean age of 69.5 years $(S D=$ 0.8 ). A freely accessible protocol paper is available. ${ }^{12}$

Standard protocol approvals, registrations, and patient consents. Ethics permission was obtained from the Multi-Centre Research Ethics Committee for Scotland (MREC/01/0/56) and Lothian Research Ethics Committee (LREC/2003/2/29). The research was performed in compliance with the Helsinki Declaration. Written informed consent was given by all participants.

Cognitive ability. Cognitive ability was assessed at about age 70 using a battery of cognitive tests administered by trained researchers. Full details have been described previously. ${ }^{12}$ The current study considered 4 cognitive domains at age 70: memory, processing speed, a general cognitive ability ("g") factor, and the Moray House Test (MHT). The g, memory, and speed factors were available from previous principal component analysis (PCA) in this sample. ${ }^{13}$ Brief descriptions of the tests are as follows.

Participants took the MHT of general cognitive ability aged 11 years in the SMS1947. The test consists of 71 items, with a maximum score of 76 , and was completed with a time limit of 45 minutes. The items included following directions, sameopposites, word classification, analogies, practical items, reasoning, proverbs, arithmetic, spatial items, mixed sentences, and cypher decoding. ${ }^{14}$ Scores on the MHT give a valid assessment of childhood cognitive ability. It was validated against the Terman-Merrill revision of the Binet Scales. ${ }^{12}$ During the cognitive assessment at age 70, participants repeated the MHT.

General cognitive ability (g) scores were obtained from the first unrotated component of a PCA of 6 Wechsler Adult Intelligence Scale-III UK subtests ${ }^{15}$ : Letter-Number Sequencing, Matrix Reasoning, Block Design, Digit Symbol, Digit Span Backward, and Symbol Search.

Processing speed scores were similarly derived by PCA of Symbol Search, ${ }^{15}$ Digit Symbol, ${ }^{15}$ inspection time,${ }^{16}$ and simple and choice reaction time. ${ }^{17}$ An overall score for memory was derived by PCA of memory measures from the Wechsler Memory Scale-III UK ${ }^{18}$ : Logical Memory (immediate and delayed recall), Spatial Span (forward and backward), and Verbal Paired Associates (immediate and delayed recall).

\begin{tabular}{|c|c|c|c|c|c|}
\hline \multicolumn{2}{|c|}{ Table 1} & \multicolumn{4}{|c|}{$\begin{array}{l}\text { Description of occupational complexity levels with data, people, and } \\
\text { things }\end{array}$} \\
\hline \multicolumn{2}{|r|}{ Data } & & People & & Things \\
\hline \multicolumn{2}{|c|}{6 Synthesizing } & 8 & Mentoring & 7 & Setting up \\
\hline \multicolumn{2}{|c|}{ Coordinating } & 7 & Negotiating & 6 & Precision working \\
\hline 4 & Analyzing & 6 & Instructing & 5 & Operating-controlling \\
\hline 3 & Compiling & 5 & Supervising & 4 & Driving-operating \\
\hline 2 & Computing & 4 & Diverting & 3 & Manipulating \\
\hline 1 & Copying & 3 & Persuading & 2 & Tending \\
\hline \multirow[t]{3}{*}{0} & \multirow[t]{3}{*}{ Comparing } & 2 & Speaking-signaling & 1 & Feed-offbearing \\
\hline & & 1 & Serving & 0 & Handling \\
\hline & & 0 & $\begin{array}{l}\text { Taking instructions- } \\
\text { helping }\end{array}$ & & \\
\hline
\end{tabular}

Reference for Dictionary of Occupational Titles. Rating scales have been reversed for the current study, so a higher score reflects greater complexity.
Occupational complexity. Participants' main lifetime occupation was obtained at the age 70 testing session. The occupational titles were matched to occupations listed in an online resource, the $D O T,{ }^{19}$ a catalog of occupations used in the United States between 1939 and 1977. In the fourth edition of the DOT, published in 1977 , more than 12,000 occupations were rated based on observations by job analysts. The DOT classifies occupations based on a 9-digit code (i.e., 092.227-010, primary school teacher). The fourth, fifth, and sixth digits represent occupational complexity with data, people, and things, respectively. Complexity ratings are summarized in table 1 . In the DOT, the most complex jobs are coded "0"; for ease of comprehension, scores have been reversed so a higher score reflects greater complexity. Occupational complexity scores were assigned to 1,066 of the 1,091 participants. Of the 25 who could not be assigned codes, 6 reported nongainful occupations (housewife), 8 gave multiple occupations, and the remaining 11 reported careers that were not classified in the DOT (for example, "facilities manager"). DOT classification was completed by one researcher (E.L.S.). A subsample of 111 occupations was recoded by the same researcher and by an independent coder to check intra- and interrater reliability using a 2-way random model intraclass correlation ${ }^{20}$ (see table e-1 on the Neurology ${ }^{\circledR}$ Web site at Neurology.org).

Deprivation. Participants were assigned a deprivation score based on matching their postcode to the Scottish Index of Multiple Deprivation (SIMD), a standardized relative ranking of geographic data areas published by the Scottish Executive, ${ }^{21}$ compiled from information about crime, education, access to services, etc. The rankings range from 1 (most deprived) to 6505 (least deprived), which have been previously collapsed in the LBC1936 to an 8-point scale. ${ }^{22}$

Years of education. The number of years of full-time education was recorded at interview at age 70 .

Statistical analyses. Analyses were performed using IBM SPSS version 19.0 (IBM Corp., Armonk, NY). General linear models were used to examine associations between occupational complexity with data, people, and things, and cognitive ability. The three occupational complexity factors were tested separately for associations with cognition, before being entered into the models simultaneously. Cognitive abilities were age 70 IQ (MHT), g factor, processing speed, and memory. Four models were fitted to the data, each including adjustments for confounding factors. Model 1 included age and sex as covariates; model 2 additionally included age 11 IQ; model 3 additionally included years of education; and the final model also included deprivation. Effect sizes are reported here as partial $\eta^{2}\left(\eta_{\mathrm{p}}^{2}\right)$.

RESULTS Participant characteristics are shown in table 2 . While men and women did not significantly differ on age, education, or deprivation, men held more complex jobs with data (men mean $=4.2$, female mean $=3.1$ ), although they did not significantly differ on the other complexity variables. Women scored higher on the MHT at age 11 whereas men had significantly higher scores for processing speed and $g$ factor at age 70. Men and women's scores for age 70 IQ and memory did not significantly differ.

Bivariate correlations (table e-2) revealed that the occupational complexity factors were significantly intercorrelated. Participants with more complex work 
Table 2 Characteristics of study population

\begin{tabular}{|c|c|c|c|c|c|c|c|c|}
\hline & \multicolumn{2}{|c|}{$\begin{array}{l}\text { Total sample } \\
\text { ( } \mathrm{N}=1,066)\end{array}$} & \multicolumn{2}{|c|}{ Male $(n=534)$} & \multicolumn{2}{|c|}{ Female $(n=532)$} & \multirow[b]{2}{*}{$t$} & \multirow[b]{2}{*}{$p$} \\
\hline & Mean & SD & Mean & SD & Mean & SD & & \\
\hline Age, y & 69.6 & 0.8 & 69.6 & 0.8 & 69.6 & 0.8 & -0.1 & 0.88 \\
\hline Education, y & 11.0 & 1.3 & 11.0 & 1.2 & 11.0 & 1.1 & 0.3 & 0.78 \\
\hline Deprivation & 6.3 & 2.9 & 6.3 & 2.0 & 6.7 & 2.2 & 1.3 & 0.18 \\
\hline Retired, \% & 95.8 & & 95.8 & & 95.8 & & 1.61 & 0.11 \\
\hline Age $11 \mathrm{IQ}$ & 100 & 15.0 & 99.0 & 15.9 & 101.0 & 14.0 & -2.2 & 0.01 \\
\hline Age 70 IQ & 100 & 14.7 & 100.6 & 15.0 & 99.5 & 14.4 & 1.2 & 0.72 \\
\hline g Factor & 0.0 & 1.0 & 0.043 & 1.032 & -0.043 & 0.966 & 1.4 & 0.04 \\
\hline Processing speed & 00.0 & 1.0 & -0.012 & 1.070 & 0.012 & 0.924 & -0.4 & 0.01 \\
\hline Memory & 0.0 & 1.0 & -0.060 & 1.070 & 0.061 & 0.980 & -2.0 & 0.45 \\
\hline Complexity with data & 3.6 & 1.6 & 4.2 & 1.5 & 3.1 & 1.6 & 11.6 & 0.00 \\
\hline Complexity with people & 2.6 & 2.0 & 2.5 & 1.5 & 2.6 & 1.9 & -0.8 & 0.43 \\
\hline Complexity with things & 3.0 & 2.6 & 3.0 & 2.8 & 2.9 & 2.4 & 1.0 & 0.34 \\
\hline
\end{tabular}

Abbreviation: $\mathrm{g}=$ general cognitive ability.

with data and people tended to have jobs with lower complexity with things $(r=-0.17$ and -0.36 respectively, $p<0.001)$. In addition, individuals who had occupations characterized by greater complexity of work with data or people tended to have better cognitive performance at age $70(r=0.16-$ $0.29)$, while participants who held occupations rated as more complex with things tended to have lower cognitive ability scores in later life (except processing speed).
General linear models. Models with individual occupational complexity factors. Four univariate general linear models were fitted for each cognitive domain separately (table 3). Complexity with data, people, and things were considered separately to examine the individual contributions of each cognitive variable. In the first models (age- and sex-adjusted), all complexity factors were significantly associated with all cognitive domains (with the exception of complexity with things and memory). Participants who held the most complex

Table 3 General linear models with individual occupational complexity factors

\begin{tabular}{|c|c|c|c|c|c|c|c|c|c|c|c|}
\hline \multirow{2}{*}{$\begin{array}{l}\text { Complexity } \\
\text { variable }\end{array}$} & \multirow{2}{*}{$\begin{array}{l}\text { Cognitive } \\
\text { variable }\end{array}$} & \multicolumn{2}{|c|}{ Unadjusted } & \multicolumn{2}{|c|}{ Model 1} & \multicolumn{2}{|c|}{ Model 2} & \multicolumn{2}{|c|}{ Model 3} & \multicolumn{2}{|c|}{ Model 4} \\
\hline & & $p$ & $\eta_{p}^{2}$ & p & $\eta_{p}^{2}$ & $p$ & $\eta_{p}^{2}$ & p & $\eta_{p}^{2}$ & p & $\eta_{p}^{2}$ \\
\hline \multirow[t]{4}{*}{ Data } & Age 70 IQ & 0.000 & 0.10 & 0.000 & 0.10 & 0.000 & 0.03 & 0.13 & 0.02 & 0.260 & 0.02 \\
\hline & g Factor & 0.000 & 0.10 & 0.000 & 0.10 & 0.000 & 0.03 & 0.000 & 0.02 & 0.001 & 0.02 \\
\hline & Processing speed & 0.000 & 0.06 & 0.000 & 0.06 & 0.001 & 0.02 & 0.006 & 0.02 & 0.022 & 0.02 \\
\hline & Memory & 0.000 & 0.04 & 0.000 & 0.05 & 0.412 & 0.01 & 0.680 & 0.00 & 0.675 & 0.00 \\
\hline \multirow[t]{4}{*}{ People } & Age 70 IQ & 0.0000 & 0.15 & 0.000 & 0.20 & 0.000 & 0.05 & 0.000 & 0.03 & 0.001 & 0.03 \\
\hline & g Factor & 0.000 & 0.13 & 0.000 & 0.13 & 0.000 & 0.04 & 0.001 & 0.03 & 0.003 & 0.02 \\
\hline & Processing speed & 0.000 & 0.07 & 0.000 & 0.07 & 0.005 & 0.01 & 0.288 & 0.01 & 0.465 & 0.01 \\
\hline & Memory & 0.000 & 0.08 & 0.000 & 0.08 & 0.005 & 0.02 & 0.107 & 0.01 & 0.112 & 0.01 \\
\hline \multirow[t]{4}{*}{ Things } & Age 70 IQ & 0.000 & 0.03 & 0.000 & 0.04 & 0.141 & 0.01 & 0.187 & 0.01 & 0.201 & 0.01 \\
\hline & g Factor & 0.000 & 0.03 & 0.000 & 0.03 & 0.559 & 0.01 & 0.507 & 0.01 & 0.674 & 0.00 \\
\hline & Processing speed & 0.000 & 0.03 & 0.000 & 0.03 & 0.394 & 0.01 & 0.289 & 0.01 & 0.337 & 0.01 \\
\hline & Memory & 0.012 & 0.02 & 0.070 & 0.01 & 0.543 & 0.01 & 0.523 & 0.01 & 0.495 & 0.00 \\
\hline
\end{tabular}

Abbreviations: $\eta^{2}$ p = partial $\eta^{2} ; g=$ general cognitive ability.

Data $=$ complexity with data; people = complexity with people; things = complexity with things. Models considered complexity with data, people, and things as independent variables (separately), with each cognitive variable as a dependent variable.

Model 1 included age and sex as covariates; model 2 additionally included age 11 IQ; model 3 additionally included years of education; model 4 additionally included deprivation. 
jobs with data, people, or things tended to score more highly across the cognitive domains examined. The largest effect sizes were observed for age 70 IQ with complexity with data and people $\left(\eta_{p}^{2}=0.10\right.$ and 0.20 , respectively). These effects were heavily attenuated by the addition of age 11 IQ. In the final models, the only surviving associations were for complexity with data, which remained significantly associated with age 70 IQ $\left(\eta_{p}^{2}=0.02\right)$, g factor $\left(\eta_{p}^{2}=0.02\right)$, processing speed $\left(\eta_{\mathrm{p}}^{2}=0.02\right)$, and complexity with people, which was significantly associated with age 70 IQ $\left(\eta_{p}^{2}=0.03\right)$ and $g$ factor $\left(\eta_{p}^{2}=0.02\right)$. Participants with occupations characterized by higher complexity with data or people tended to have better scores for general cognitive ability, and those with more complex jobs with data also tended to have better processing speed scores. There were no associations with any of the cognitive domains and complexity with things in the fully adjusted models.

Models with the 3 occupational complexity factors entered simultaneously. The results of the main analyses with data, people, and things entered simultaneously are displayed in table 4. Examination of the models including interaction terms revealed no significant interactions between any of the occupational complexity factors and sex; the results were therefore not separated by sex, and interactions were not included in subsequent analyses.

The first models (age- and sex-adjusted) revealed that all occupational complexity factors were associated with performance on all cognitive domains; that is, people who had occupations characterized by higher complexity tended to perform better. The largest effect sizes were for the associations between complexity with people and age 70 IQ $\left(\eta_{p}^{2}=\right.$ $0.06)$ and $g$ factor scores $\left(\eta_{p}^{2}=0.06\right)$. The addition of age 11 IQ substantially attenuated these effects. Surviving associations were seen for complexity of data, which remained significantly associated with age 70 IQ, g factor, and processing speed. Complexity with people remained significantly associated with age 70 IQ, g factor, and memory. The associations of complexity with people and $\mathrm{g}$ factor and memory survived full adjustment (both $\eta_{p}^{2}=0.02$ ); participants with occupations rated as more complex with people tended to perform better in terms of their cognitive ability. Complexity with data remained positively associated with $\mathrm{g}$ factor and processing speed in the final model, although this was slightly attenuated by the addition of deprivation (both $\eta_{p}^{2}=0.01$ ). No effects of complexity with things across any of the cognitive domains survived the addition of age 11 IQ.

DISCUSSION The present study's findings support the hypothesis that higher complexity of work is associated with later-life cognitive performance. In the LBC1936, individuals who held occupations with higher levels of complexity with data and people had better cognitive performance at age 70 . After controlling for early-life cognitive ability, years of education, and deprivation, individuals with occupations characterized with higher complexity of work with people remained significantly associated with $\mathrm{g}$ factor and memory scores. Effects of complexity of work with data remained significant

\begin{tabular}{|c|c|c|c|c|c|c|c|c|c|c|c|}
\hline \multirow{3}{*}{$\begin{array}{l}\text { Table } 4 \\
\begin{array}{l}\text { Cognitive } \\
\text { variable }\end{array}\end{array}$} & \multirow{3}{*}{$\begin{array}{l}\text { Complexity } \\
\text { variable }\end{array}$} & with al & occup & tional $\mathrm{f}$ & tors & tered $\mathrm{s}$ & nultar & ously & & & \\
\hline & & \multicolumn{2}{|c|}{ Unadjusted } & \multicolumn{2}{|c|}{ Model 1} & \multicolumn{2}{|c|}{ Model 2} & \multicolumn{2}{|c|}{ Model 3} & \multicolumn{2}{|c|}{ Model 4} \\
\hline & & $p$ & $\eta_{p}^{2}$ & $p$ & $\eta_{p}^{2}$ & $p$ & $\eta_{p}^{2}$ & $p$ & $\eta_{p}^{2}$ & $p$ & $\eta^{2} p$ \\
\hline \multirow[t]{3}{*}{ Age 70 IQ } & Data & 0.000 & 0.05 & 0.000 & 0.04 & 0.025 & 0.02 & 0.073 & 0.01 & 0.091 & 0.01 \\
\hline & People & 0.000 & 0.05 & 0.000 & 0.06 & 0.021 & 0.02 & 0.114 & 0.01 & 0.144 & 0.01 \\
\hline & Things & 0.000 & 0.03 & 0.000 & 0.04 & 0.113 & 0.01 & 0.149 & 0.01 & 0.165 & 0.01 \\
\hline \multirow[t]{3}{*}{ g Factor } & Data & 0.000 & 0.05 & 0.000 & 0.04 & 0.004 & 0.02 & 0.016 & 0.02 & 0.034 & 0.01 \\
\hline & People & 0.000 & 0.06 & 0.000 & 0.06 & 0.002 & 0.03 & 0.026 & 0.02 & 0.046 & 0.02 \\
\hline & Things & 0.000 & 0.03 & 0.000 & 0.03 & 0.192 & 0.01 & 0.224 & 0.01 & 0.292 & 0.01 \\
\hline \multirow[t]{3}{*}{ Processing speed } & Data & 0.000 & 0.05 & 0.000 & 0.03 & 0.010 & 0.02 & 0.026 & 0.02 & 0.044 & 0.01 \\
\hline & People & 0.021 & 0.02 & 0.017 & 0.02 & 0.796 & 0.01 & 0.819 & 0.00 & 0.903 & 0.00 \\
\hline & Things & 0.000 & 0.03 & 0.000 & 0.03 & 0.123 & 0.01 & 0.153 & 0.01 & 0.173 & 0.01 \\
\hline \multirow[t]{3}{*}{ Memory } & Data & 0.000 & 0.03 & 0.000 & 0.03 & 0.051 & 0.01 & 0.90 & 0.01 & 0.094 & 0.01 \\
\hline & People & 0.000 & 0.05 & 0.000 & 0.05 & 0.004 & 0.02 & 0.032 & 0.02 & 0.032 & 0.02 \\
\hline & Things & 0.001 & 0.02 & 0.009 & 0.02 & 0.123 & 0.01 & 0.128 & 0.01 & 0.127 & 0.01 \\
\hline
\end{tabular}

Abbreviations: $\eta^{2}{ }_{p}=$ partial $\eta^{2} ; g=$ general cognitive ability.

Data $=$ complexity with data; people $=$ complexity with people; things $=$ complexity with things. All models included complexity with data, people, and things as independent variables, with each cognitive variable as a dependent variable. Model 1 included age and sex as covariates; model 2 additionally included age $11 \mathrm{IQ}$; model 3 additionally included years of education; model 4 additionally included deprivation. 
for $\mathrm{g}$ factor and processing speed. The effects were small, accounting for approximately $1 \%$ to $2 \%$ of the variance, comparable to other predictors such as the association between smoking and cognition in later life in the LBC1936. ${ }^{23}$ The findings are consistent with those reported previously $y^{2-4,24,25}$ and provide support for occupational complexity as a modest predictor of cognitive performance in later life, independently of prior ability.

Given that most attenuation of the association between occupational complexity and cognitive ability occurred after the addition of age 11 IQ (the reduction in effect size being approximately $50 \%$ $66 \%$ ), the findings additionally provide evidence of preserved differentiation. That is, engagement in complex activities (in this case occupationally complex) is partly a consequence of the lifetime stability of cognitive ability. However, the findings further show evidence of differential preservation. That is, engaging in complex environments, such as those characterized by complex occupational demands, may help to preserve cognitive function in later life and could be one of many factors that account for individual differences in cognitive performance in older age. The current study benefits by being able to address the likelihood of preserved differentiation; while the effects of occupational complexity were indeed attenuated by the addition of early-life ability, some subtle, significant effects remained. It is important to note this attenuation, because it suggests that studies not accounting for prior ability may overestimate the beneficial effect of complex occupational environments on later cognition. Notwithstanding this caveat, the current results suggest that occupational complexity slightly benefits later-life cognitive performance, independently of the lifelong stability of cognitive ability. Direct causation cannot be inferred from the current study; however, previous studies have shown reciprocal effects between level of ability and occupational complexity. ${ }^{25,26}$

Mechanisms underlying how occupational demands may affect cognitive abilities are disputed. One theory is that complex lifestyles increase the amount of cognitive or brain reserve. It has been suggested that environmental factors, such as occupational complexity, may affect a person's cognitive abilities by increasing structural brain reserve, increasing neural efficacy, or alternatively may help to utilize compensatory pathways. ${ }^{6}$ Recent findings suggest that there are multiple biological pathways that mediate the relationship between stimulating lifestyles and cognitive abilities, through which stimulating lifestyles may have protective effects against pathology ${ }^{27}$ or indeed normal aging.

Complexity of work with people had the largest association with 2 of the 4 cognitive domains. This corresponds to recent research exploring associations between social engagement and cognitive aging. It has been postulated that greater levels of social engagement and social support are associated with a lower risk of cognitive impairment in later life..$^{28-30}$ A similar study ${ }^{24}$ found that, in a sample of male twins, having a job that had a high degree of social engagement was a significant predictor of later-life ability. In the current study, complexity with people was associated with both memory and $\mathrm{g}$ factor. It is possible that it is this "social" aspect of occupational complexity with people that may be an important determinant of later-life cognitive functioning.

Sex differences have not been explored before in the literature despite apparent sex differences in occupations. $^{31}$ It might be expected that because men, especially given the generation of the current study's participants, tended to have more-demanding occupations, they might also have had a slight cognitive advantage in old age. However, the current study found no significant effects of sex by any of the occupational complexity factors. Further exploration of male and female occupations revealed some differences. The most common occupations held by women were clerical (secretaries, etc.), teaching, and nursing. Within these occupations, teaching had the highest rating for complexity with people and made up approximately $10 \%$ of female careers (3\% of male). For men, managerial, supervisory, and company directors were the most common positions with the highest ratings for complexity with people. So, although the careers that men held with higher levels of complexity with people were qualitatively different to women, the levels of complexity with people remained equivalent.

The study has some limitations. Occupational complexity is a hypothesized construct and DOT codes are based on national survey data and may not fully express an individual's engagement in their career. A self-reported measure might better reflect this. In addition, the complexity with things variable had a particularly skewed distribution; analyses were completed with a dichotomized things variable, which was not associated with any of the cognitive variables, although some of the main findings were slightly altered. Given these small changes, it is important that the current results are replicated in other cohorts with prior cognitive ability data, occupational ratings, and cognition in old age.

Furthermore, the DOT codes were derived from 1970 US census data, which may not be directly applicable to a UK sample, although previous epidemiologic research has supported the use of these as valid measures of occupational complexity. ${ }^{4,32} \mathrm{~A}$ small proportion of the sample was not coded for occupational complexity, mostly because the occupations they reported were not classified in the DOT; their number was small and their exclusion from analysis would be unlikely to have affected the main findings. 
In addition, occupational duration was not available. If occupational characteristics affect important life outcomes (such as cognitive ability or change), length of exposure might be an important factor. Because the current study did not have access to these data, it is an open question of whether there is a doseresponse effect in the association between occupational complexity and cognition. Given the sample size, and therefore the statistical power of the current study, traditional statistical cutoffs would be likely to afford results of statistical significance even when effect sizes were very small. As previously acknowledged, the effect sizes are similar to those in prior literature examining other determinants of cognitive aging. The cohort also represents a healthier subset of the SMS1947; this "survivor" effect may have restricted the range of cognitive outcome scores. Finally, age 11 IQ explains approximately $50 \%$ of variance in cognitive performance in later life, ${ }^{33}$ but probably does not fully capture peak adult cognition, because of cognitive development that takes place between age 11 and cognitive maturity.

The availability of early-life ability measures is a rare advantage of the study. It is a relatively large sample, and the narrow age of the participants is an advantage because it avoids the confounding effects of chronological age and cohort. Compared with other studies in the literature, the LBC1936 study has a broad battery of cognitive assessments. A further strength of the study is that it is ongoing. Planned follow-ups exploring the continuing effects of complexity of lifetime work throughout old age will be possible and may help further our understanding of the conditions that promote healthy cognitive aging. Future studies will have the opportunity to additionally include brain imaging measures, which may give insight into neurologic mechanisms linking occupational characteristic to later-life cognitive change.

In summary, the current study supports an association between more complex lifetime occupations and better cognitive abilities in later life. Of note, the evidence in favor of the differential preservation of cognitive abilities has been examined in the context of accounting for the likelihood of persevered differentiation, a major issue in the search for determinants of cognitive aging.

\section{AUTHOR CONTRIBUTIONS}

E.L. Smart: study concept and design, data acquisition, coding of occupational complexity ratings, analysis and interpretation, drafting and revising the manuscript A.J. Gow: study concept and design, analysis and interpretation, and revising the manuscript. I.J. Deary: study concept, study management, discussion of analysis and interpretation, and revising the manuscript.

\section{ACKNOWLEDGMENT}

The authors thank the LBC1936 Study participants, the members of the LBC1936 study team for data collection, collation, and checking, and the Scottish Council for Research in Education for allowing access to the SMS1947. The authors thank the nurses and other staff at the Wellcome Trust Clinical Research Facility, Western General Hospital, in Edinburgh. The work was undertaken in The University of Edinburgh Centre for Cognitive Ageing and Cognitive Epidemiology, part of the cross-council Lifelong Health and Wellbeing Initiative (MR/K026992/1).

\section{STUDY FUNDING}

Supported by a Research Into Ageing programme grant (to I.J.D.) and the Age UK-funded Disconnected Mind project (http://www. disconnectedmind.ed.ac.uk) to I.J.D., with additional funding from the Medical Research Council (to I.J.D.). Funding also received from the Biotechnology and Biological Sciences Research Council (BBSRC).

\section{DISCLOSURE}

The authors report no disclosures relevant to the manuscript. Go to Neurology.org for full disclosures.

Received May 9, 2014. Accepted in final form September 10, 2014.

\section{REFERENCES}

1. Gow AJ, Avlund K, Mortensen EL. Occupational characteristics and cognitive aging in the Glostrup 1914 Cohort. J Gerontol B Psychol Sci Soc Sci 2014;115:228-236.

2. Finkel D, Andel R, Gatz M, Pedersen NL. The role of occupational complexity in trajectories of cognitive aging before and after retirement. Psychol Aging 2009;24:563.

3. Marquie JC, Duarte LR, Bessières P, Dalm C, Gentil C, Ruidavets JB. Higher mental stimulation at work is associated with improved cognitive functioning in both young and older workers. Ergonomics 2010;53:1287-1301.

4. Potter GG, Helms MJ, Plassman BL. Associations of job demands and intelligence with cognitive performance among men in late life. Neurology 2008;70:1803-1808.

5. Andel R, Kåreholt I, Parker MG, Thorslund M, Gatz M. Complexity of primary lifetime occupation and cognition in advanced old age. J Aging Health 2007;19:397-415.

6. Stern Y. Cognitive reserve in ageing and Alzheimer's disease. Lancet Neurol 2012;11:1006-1012.

7. Whalley LJ, Deary IJ, Appleton CL, Starr JM. Cognitive reserve and the neurobiology of cognitive aging. Ageing Res Rev 2004;3:369-382.

8. Valenzuela MJ, Sachdev P. Brain reserve and cognitive decline: a non-parametric systematic review. Psychol Med 2006;36:1065-1073.

9. Kröger E, Andel R, Lindsay J, Benounissa Z, Verreault R, Laurin D. Is complexity of work associated with risk of dementia? The Canadian Study of Health and Aging. Am J Epidemiol 2008;167:820-830.

10. Salthouse TA. Mental exercise and mental aging: evaluating the validity of the "use it or lose it" hypothesis. Perspect Psychol Sci 2006;1:68-87.

11. Salthouse TA, Berish DE, Miles JD. The role of cognitive stimulation on the relations between age and cognitive functioning. Psychol Aging 2002;17:548.

12. Deary IJ, Gow AJ, Taylor MD, et al. The Lothian Birth Cohort 1936: a study to examine influences on cognitive ageing from age 11 to age 70 and beyond. BMC Geriatr 2007;7:28.

13. Corley J, Jia X, Brett CE, et al. Alcohol intake and cognitive abilities in old age: the Lothian Birth Cohort 1936 study. Neuropsychology 2011;25:166.

14. Scottish Council for Research in Education. The Trend of Scottish Intelligence: A Comparison of the 1947 and 1932 Surveys of the Intelligence of Eleven-Year-Old Pupils. London: University of London Press; 1949. 
15. Wechsler D. WAIS-IIIUK Administration and Scoring Manual. London: Psychological Corporation; 1998a.

16. Deary IJ, Simonotto E, Meyer M, et al. The functional anatomy of inspection time: an event-related fMRI study. Neuroimage 2004;22:1466-1479.

17. Cox BD, Hupper FA, Whichelow MJ. The Health and Lifestyle Survey: Seven Years On. A Longitudinal Study of a Nationwide Sample, Measuring Changes in Physical and Mental Health, Attitudes and Lifestyle. Aldershot, UK: Dartmouth Publishing Co.; 1993.

18. Wechsler D. WMS-IIIUK Administration and Scoring Manual. London: Psychological Corporation; 1998b.

19. United States Employment Service. Dictionary of Occupational Titles, 4th ed, revised. Washington, DC: Superintendent of Documents, US Government Printing Office; 1977. Available at: www.occupationalinfo.org. Accessed June 11, 2012.

20. Shrout PE, Fleiss JL. Intraclass correlations: uses in assessing rater reliability. Psychol Bull 1979;86:420.

21. Scottish Executive. Scottish Index of Multiple Deprivation 2006. Edinburgh: Scottish Executive; 2006.

22. Johnson W, Gow AJ, Corley J, Starr JM, Deary IJ. Location in cognitive and residential space at age 70 reflects a lifelong trait over parental and environmental circumstances: the Lothian Birth Cohort 1936. Intelligence 2010;38:402-411.

23. Taylor M, Hart C, Davey Smith G, et al. Childhood mental ability and smoking cessation in adulthood: prospective observational study linking the Scottish Mental Survey 1932 and the Midspan studies. J Epidemiol Community Health 2003;57:464-465.

24. Potter GG, Plassman BL, Helms MJ, Foster SM, Edwards NW. Occupational characteristics and cognitive performance among elderly male twins. Neurology 2006; 67:1377-1382.

25. Schooler C. Use it—and keep it, longer, probably: a reply to Salthouse (2006). Perspect Psychol Sci 2007;2:24-29.

26. Schooler C, Mulatu MS, Oates G. The continuing effects of substantively complex work on the intellectual functioning of older workers. Psychol Aging 1999;14:483.

27. Valenzuela MJ, Matthews FE, Brayne C, et al. Multiple biological pathways link cognitive lifestyle to protection from dementia. Biol Psychiatry 2012;71:783-791.

28. Crooks VC, Lubben J, Petitti DB, Little D, Chiu V. Social network, cognitive function, and dementia incidence among elderly women. Am J Public Health 2008; 98:1221.

29. Okabayashi $\mathrm{H}$, Liang J, Krause $\mathrm{N}$, Akiyama $\mathrm{H}$, Sugisawa H. Mental health among older adults in Japan: do sources of social support and negative interaction make a difference? Soc Sci Med 2004;59:2259-2270.

30. Gow AJ, Pattie A, Whiteman MC, Whalley LJ, Deary IJ. Social support and successful aging. J Individ Differ 2007; 28:103-115.

31. Office for National Statistics. Statistical Bulletin: Annual Survey of Hours and Earnings. London:Office for National Statistics; 2012.

32. Andel R, Crowe M, Pedersen NL, et al. Complexity of work and risk of Alzheimer's disease: a population-based study of Swedish twins. J Gerontol B Psychol Sci Soc Sci 2005;60:251-258.

33. Gow AJ, Johnson W, Pattie A, et al. Stability and change in intelligence from age 11 to ages 70, 79, and 87: the Lothian Birth Cohorts of 1921 and 1936. Psychol Aging 2011;26:232

\section{This Week's Neurology ${ }^{\circledR}$ Podcast}

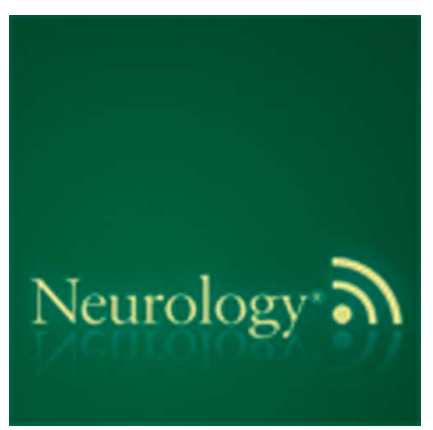

Physician burnout: A neurologic crisis (see p. 2302)

This podcast begins and closes with Dr. Robert Gross, Editor-in-Chief, briefly discussing highlighted articles from the December 9, 2014, issue of Neurology. In the second segment, Dr. Ted Burns talks with Dr. Bruce Sigsbee about his paper on physician burnout. Dr. James Addington then reads the e-Pearl of the week about colloid cysts. In the next part of the podcast, Dr. Stacey Clardy focuses her interview with Dr. Joseph Dalmau on his career as a neurologist.

Disclosures can be found at Neurology.org.

At Neurology.org, click on "RSS" in the Neurology Podcast box to listen to the most recent podcast and subscribe to the RSS feed.

CME Opportunity: Listen to this week's Neurology Podcast and earn 0.5 AMA PRA Category

$1 \mathrm{CME}$ Credits ${ }^{\mathrm{TM}}$ by answering the multiple-choice questions in the online Podcast quiz. 


\title{
Neurology
}

\section{Occupational complexity and lifetime cognitive abilities}

\author{
Emily L. Smart, Alan J. Gow and Ian J. Deary
}

Neurology 2014;83;2285-2291 Published Online before print November 19, 2014

DOI 10.1212/WNL.0000000000001075

This information is current as of November 19, 2014

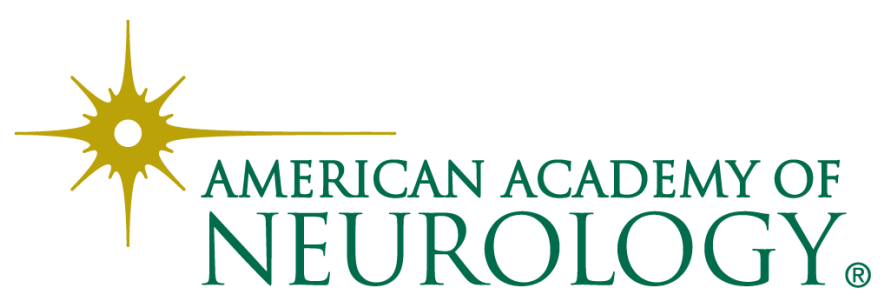




\section{Updated Information \& Services}

\section{Supplementary Material}

References

Citations

Subspecialty Collections

\section{Errata}

Permissions \& Licensing

\section{Reprints}

including high resolution figures, can be found at: http://n.neurology.org/content/83/24/2285.full

Supplementary material can be found at: http://n.neurology.org/content/suppl/2014/11/19/WNL.0000000000001 075.DC1

This article cites 26 articles, 3 of which you can access for free at: http://n.neurology.org/content/83/24/2285.full\#ref-list-1

This article has been cited by 1 HighWire-hosted articles: http://n.neurology.org/content/83/24/2285.full\#\#otherarticles

This article, along with others on similar topics, appears in the following collection(s):

\section{All epidemiology}

http://n.neurology.org/cgi/collection/all_epidemiology

Cognitive aging

http://n.neurology.org/cgi/collection/cognitive_aging

Cohort studies

http://n.neurology.org/cgi/collection/cohort_studies

Intelligence

http://n.neurology.org/cgi/collection/intelligence

An erratum has been published regarding this article. Please see next page or:

/content/84/16/1721.2.full.pdf

Information about reproducing this article in parts (figures,tables) or in its entirety can be found online at:

http://www.neurology.org/about/about_the_journal\#permissions

Information about ordering reprints can be found online:

http://n.neurology.org/subscribers/advertise

Neurology ${ }^{\circledR}$ is the official journal of the American Academy of Neurology. Published continuously since 1951, it is now a weekly with 48 issues per year. Copyright @ 2014 American Academy of Neurology. All rights reserved. Print ISSN: 0028-3878. Online ISSN: 1526-632X.

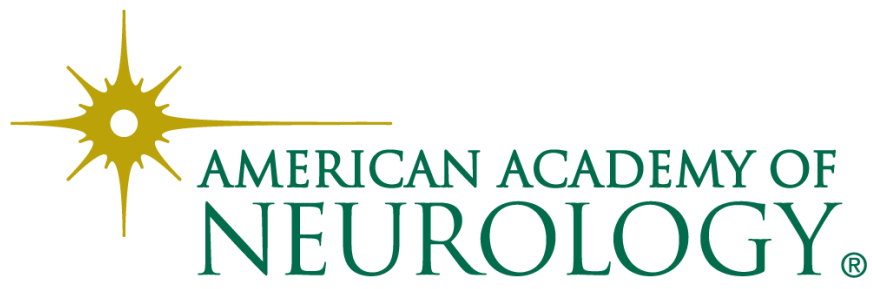


(WWS) caused by a mutation in the POMT1 gene. Neuromuscul Disord 2005;15:271-275.

4. Hara Y, Balci-Hayta B, Yoshida-Moriguchi T, et al. A dystroglycan mutation associated with limb-girdle muscular dystrophy. N Engl J Med 2011;364:939-946.

\section{RASMUSSEN ENCEPHALITIS AND COMORBID AUTOIMMUNE DISEASES: A WINDOW INTO DISEASE MECHANISM?}

Isabelle Korn-Lubetzki, Jerusalem: Amrom et al. ${ }^{1}$ reported 4 patients with Rasmussen encephalitis (RE) who were subsequently diagnosed with comorbid autoimmune conditions (ulcerative colitis and Crohn disease in 2). This association raises the possibility of immunogenetic susceptibility in these patients. ${ }^{1}$

We reported a very unusual presentation of RE in a young girl. ${ }^{2}$ Diagnosis was difficult because the presenting symptom was hemiparesis while the seizures developed only 4 months later. An extended immunologic screening revealed positive serum antinuclear antibodies at 1:80 dilution, as well as extractable nuclear antigen, anti-Sm, and anti-RNP antibodies. Serum anti-GluR3 antibodies were negative. Family history disclosed ulcerative colitis both in the mother and maternal aunt. This case reinforced the association of $\mathrm{RE}$ with autoimmune diseases, particularly colitis.

Author Response: Dina Amrom, Montreal; Demet Kinay, Istanbul; Frederick Andermann, Eva Andermann, Montreal: The authors thank Dr. KornLubetzki for updating their case ${ }^{2}$ and noting the familial occurrence of autoimmune disease (AID) and ulcerative colitis in the mother and maternal aunt of the patient. In 1991, an immunogenetic susceptibility for RE had been suggested. ${ }^{3}$ To our knowledge, occurrence of an AID, Behçet disease, in a firstdegree relative of a patient with $\mathrm{RE}$, was first reported in 2008. ${ }^{4}$ In our recent article, we reported another AID, diabetes type 1 , in the brother of one individual with RE. ${ }^{1}$ Several examples of multiple AIDs occurring in individual patients and within families with a given AID suggested a common underlying etiology, and the concept of shared autoimmunity. ${ }^{5}$ We expect that an increasing number of clinical observations of comorbid AID in individual patients with RE, as well as of the occurrence of AIDs in their relatives, will be reported. Detailed medical and family histories and molecular analysis in a large series of probands with $\mathrm{RE}$ and their families would be required to confirm the evidence for a shared immunogenetic predisposition between RE and common AIDs with complex inheritance, including shared susceptibility loci, and specific alleles.

(C) 2015 American Academy of Neurology

1. Amrom D, Kinay D, Hart Y, et al. Rasmussen encephalitis and comorbid autoimmune diseases: a window into disease mechanism? Neurology 2014;83:1049-1055.

2. Korn-Lubetzki I, Bien CG, Bauer J, et al. Rasmussen encephalitis with active inflammation and delayed seizures onset. Neurology 2004;62:984-986.

3. Andermann E, Oguni H, Guttmann RD, Osterland CK, Antel JP, Eeg-Olofsson O. Genetic aspects of chronic encephalitis. In: Andermann F, ed. Chronic Encephalitis and Epilepsy: Rasmussen's Syndrome. Boston: Butterworth-Heinemann; 1991:167-175.

4. Kinay D, Bebek N, Vanli E, Gurses C, Gokyigit A, Andermann F. Rasmussen's encephalitis and Behcet's disease: autoimmune disorders in first degree relatives. Epileptic Disord 2008;10:319-324.

5. Alarcon-Segovia D. Shared autoimmunity: a concept for which the time has come. Curr Rheumatol Rep 2004;6: 1771-1774.

\section{CORRECTION}

Occupational complexity and lifetime cognitive abilities

In the article "Occupational complexity and lifetime cognitive abilities" by E.L. Smart et al. (Neurology ${ }^{\circledR}$ 2014;83:2285-2291), there are 2 errors in table 3. In the top row, under Models 3 and 4, the $p$ values should read 0.013 and 0.026 , rather than 0.13 and 0.260 as originally published. The authors regret the error. 